\title{
RISK PREMIA IN THE CZECH MONEY MARKET
}

\author{
Martin Pohl \\ University of Economics, Prague \\ Zlonicka 703/2, Prague, Czech Republic \\ E-mail: pmartin@centrum.cz
}

\begin{abstract}
We estimate risk premia in the Czech money market and we pay special attention to the 2008-2009 crisis period. Our results imply a rising forward premium and we argue that the error correction model is the most appropriate method, but median may be used as a first guess estimator. We estimated the term premium between the policy rate and various money market interest rates. In this context, $A R C H$ models proved to be useful in reflection of non-stationarity observed in the data. The financial crisis caused a structural break in our data sample, but the impact on the forward premium was only brief and forward premia normalized quickly. The widening of the term premium proved to be much more persistent, although it declined significantly since the peak of the crisis.
\end{abstract}

Keywords: financial crisis, expectations hypothesis, money market, PRIBOR, forwards

JEL Classification: E43, C32

\section{Introduction}

Money market interest rates serve as benchmarks for a significant portion of loans, bonds and derivatives (IMF, 2008). They are a key component of the monetary policy transmission channel. Disruptions, therefore, have a large impact on other segments of financial markets, the financial system, the economy and the effectiveness of monetary policy. Money markets were also the epicentre of the 2008/2009 financial crisis and have received a lot of attention since then. There are several studies that deal with money markets in developed countries, but only few of them deal with the crisis in the context of emerging markets.

In our paper, we focus on Czech money markets and we pay special attention to the $2008 / 2009$ crisis period. Our starting point is the expectation hypothesis of the term structure of interest rates. The expectation hypothesis offers an intuitive framework that forms the core of most standard interest rate structure models and is applied by practitioners in their investment decisions, although its empirical support is not unanimous in literature (Gravelle, 1998 or Kotlán, 1999). Using this framework, we estimate the forward premium (the difference between the expected market rate and corresponding forward rate 
agreement) and the term premium (the difference between the policy rate and key money market rates). Also, we test whether the premia changed during the crisis.

\section{$1 \quad$ Biased expectation hypothesis}

The starting point of our analysis is the biased expectation theory and we offer its brief overview in this section. There are more versions of expectation theory, but in the context of our paper the forward premium and term premium concepts are relevant (Costa, 2007). Biased expectation theory assumes that forward interest rates reflect the expected path of short-term interest rates and risk premia. In applying expectation theory restrictions, we may decompose the forward rate $f_{t}^{(h, h+k)}$ into the expected short-term interest $E_{t}\left(y_{t+h}^{k}\right)$ and forward premium $f p_{t}^{f}$, where $\mathrm{k}$ denotes $\mathrm{k}$-period instrument and $\mathrm{h}$ means "h-months-ahead" horizon.

$$
f_{t}^{(h, h+k)}=f p_{t}^{f}+E_{t}\left(y_{t+h}^{k}\right)
$$

Standard expectation theory implies that a forward premium is higher for longer-dated instruments that bear more interest rate risks for the investor. We assume a constant forward premium which is a standard approach. We try to derive market expectations from the actual development of interest rates after removing random noise, assuming a constant forward premium. Equation (1) may then be transformed into equation (2) for three-month interbank deposits represented by variable $y_{t+h}^{3}$, which builds the base of our empirical analysis.

$$
f_{t}^{(h, h+3)}=\alpha+\beta^{*} y_{t+h}^{3}+\varepsilon_{t}
$$

A term premium is a premium based on the yield to maturity hypothesis that assumes that yield on a zero-coupon bond $y_{t}^{m}$ (deposits) that matures in $m$ periods (months) is equal to the average of one-period yields. In this context, term premium $t p_{t}^{m}$ represents excess return over rolling over one-period bonds (deposits). We use linear approximation, but we agree that using compounded returns would be more precise.

$$
y_{t}^{m}=t p_{t}^{m}+\frac{1}{m} * E\left(\sum_{i=1}^{m} y_{t+i-1}^{1}\right)
$$

We would expect both forward and term premium to increase with rising maturity. We assume them to be constant in our paper, but we discuss the impact of structural breaks. In our analysis, we compare the CNB's two-week 
repo rate and various deposit rates. The repo rate is the leading interest rate for market players and spreads below corresponding two-week deposits are pretty low, averaging 5-10bp over most of the sample period, although they widened significantly during the crisis period.

\section{Methodology and data}

We estimated the forward and term premium using different methods. We applied cointegration analysis, forward regression, $\mathrm{ARCH}$ model and basic descriptive statistics. In the Czech context, a similar approach was pplied by Kotlán (1999). In contrast to him, we applied an error correction model that was employed by other researchers analysing foreign money markets. Early works applying cointegration technique similar to our approach may be found in Gravelle, Muller, Stréliski (1998) who deal with Canadian money markets. For Euro markets we found Costa, Galvão (2007) and Durré, Snorre, Pilegaard (2003) useful, although they deal with implied forwards. A comprehensive comparison of different instruments for US markets is provided by Gürkaynak, Sack, Swanson (2007).

Our data set includes three month PRIBOR and corresponding forward rate agreements (FRA) starting in one, three, six and nine months. Three month PRIBOR rates and other money market rates are from the CNB. FRA rates (ask) quotations and data used for illustrative purposes in the financial crisis section are from Bloomberg. We use monthly averages with a sample start in January 2000. There are three reasons for this choice. Firstly, the data in 1997 and 1998 were impacted by the 1997 financial crisis, when interest rates reached high double digit levels. Secondly, the Euro was introduced in 1999 and also the CNB had a one-year experience with inflation targeting. Both events could have caused structural breaks in the data sample. The sample ends in mid-2010, when the consequences of the last financial crisis continued to fade away.

The relatively high level of interest rates (see Figure 1 ) at the beginning of the sample was caused by the financial crisis in 1997 and the CNB's reaction to the crisis. The subsequent decline reflects remarkable disinflation and maturing of the Czech economy and financial markets, which pressed Czech interest rates to levels comparable to mature markets. This trend was interrupted by two monetary tightening cycles and by the financial crisis, which impacted money markets in 2008/2009. 
Figure 1 Selected money market interest rates

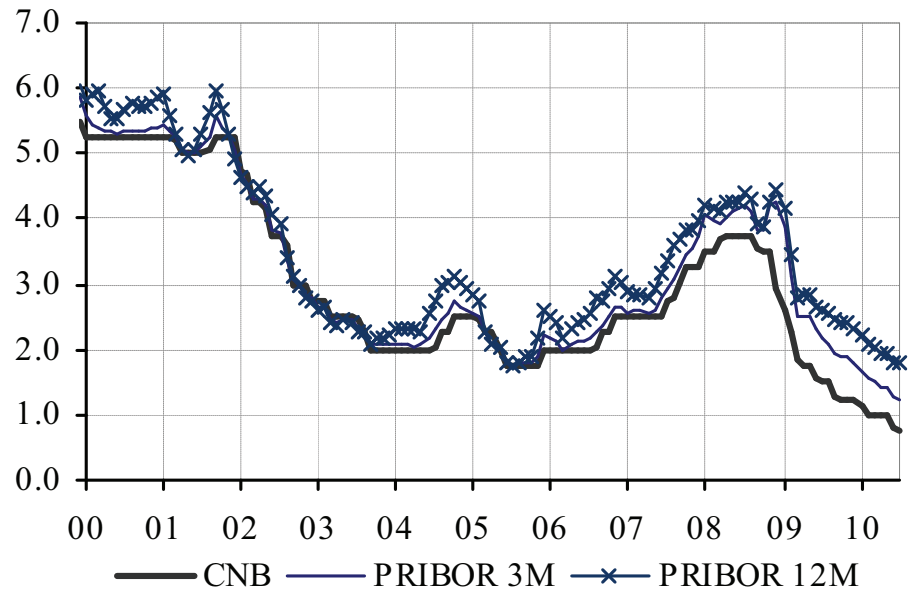

Source: CNB

Descriptive statistics for key variables are provided in Table 1. All data were calculated as monthly averages. Our data sample shows important characteristics that we study further in our paper. Firstly, we may observe that the interest rate level rises with maturity. This is consistent with an upward sloping yield curve, with risk premia rising depending on maturity. Secondly, the volatility seems to be slightly higher for shortest maturities, although less visible for FRAs. Thirdly, all distributions are skewed towards higher values as indicated by positive skewness and a lower median than average. This is a typical picture, but may even be reinforced by the impact of 2008/2009 financial crisis.

Table 1 Descriptive statistics (part I) - money market interest rates in \%

\begin{tabular}{lccccccc}
\hline Statistics & Cnb & MM 1M & MM 2M & MM 3M & MM 6M & MM 9M & MM 12M \\
\hline Mean & 2.94 & 3.06 & 3.10 & 3.15 & 3.24 & 3.32 & 3.40 \\
\hline Median & 2.50 & 2.53 & 2.56 & 2.61 & 2.69 & 2.80 & 2.91 \\
\hline Maximum & 5.25 & 5.40 & 5.48 & 5.57 & 5.73 & 5.85 & 5.98 \\
\hline Minimum & 0.75 & 1.01 & 1.11 & 1.24 & 1.52 & 1.66 & 1.75 \\
\hline Std. Dev. & 1.32 & 1.30 & 1.28 & 1.27 & 1.26 & 1.26 & 1.26 \\
\hline Skewness & 0.57 & 0.60 & 0.60 & 0.61 & 0.65 & 0.67 & 0.69 \\
\hline Kurtosis & 2.15 & 2.06 & 2.02 & 1.99 & 2.03 & 2.10 & 2.18 \\
\hline
\end{tabular}

Source: author's estimate, Czech National Bank

Interest rates are assumed to be stationary, but in finite samples they often show non-stationary behavior. We used standard tests to verify non-stationary data. Individual unit root tests give weak support to the unit root hypothesis and results are provided in Table 2. 
Table 1 Descriptive statistics (part II) - FRAs in \%

\begin{tabular}{lcccc}
\hline Statistics & FRA_1to4 & FRA_3to6 & FRA_6to9 & FRA_9to12 \\
\hline Mean & 3.24 & 3.22 & 3.32 & 3.47 \\
\hline Median & 2.70 & 2.78 & 2.88 & 3.03 \\
\hline Maximum & 6.60 & 5.86 & 6.03 & 6.66 \\
\hline Minimum & 1.25 & 1.20 & 1.27 & 1.38 \\
\hline Std. Dev. & 1.33 & 1.27 & 1.29 & 1.33 \\
\hline Skewness & 0.60 & 0.65 & 0.70 & 0.76 \\
\hline Kurtosis & 2.05 & 2.21 & 2.32 & 2.50 \\
\hline
\end{tabular}

Source: author's estimate

Table 2 Individual unit root tests (part I) - money market interest rates

\begin{tabular}{cccccccc}
\hline Test & cnb & MM 1M & MM 2M & MM 3M & MM 6M & MM 9M & MM 12M \\
\hline PP & -1.90 & -2.03 & -1.98 & -1.92 & -1.90 & -1.88 & -1.89 \\
\hline p-value & 0.05 & 0.04 & 0.05 & 0.05 & 0.05 & 0.06 & 0.06 \\
\hline ADF & -1.50 & -2.09 & -1.79 & -1.68 & -1.60 & -1.79 & -1.81 \\
\hline p-value & 0.12 & 0.04 & 0.07 & 0.09 & 0.10 & 0.07 & 0.07 \\
\hline
\end{tabular}

Legend: PP denotes Phillips-Perron test and ADF Augmented Dickey-Fuller test.

Source: author's estimate

Table 2 Individual unit root tests (part II) - FRAs

\begin{tabular}{ccccc}
\hline Test & FRA_1to4 & FRA_3to6 & FRA_6to9 & FRA_9to12 \\
\hline PP & -1.59 & -1.92 & -1.82 & -1.69 \\
\hline p-value & 0.10 & 0.05 & 0.07 & 0.09 \\
\hline ADF & -1.63 & -1.87 & -1.79 & -1.77 \\
\hline p-value & 0.10 & 0.06 & 0.07 & 0.07 \\
\hline
\end{tabular}

Source: author's estimate

Group unit root tests are recommended for their higher power. They provide more conclusive support for unit roots. We divided our sample into two subsamples. The first subsample includes money market interest rates and policy rate. The second subsample includes FRAs and three month PRIBOR. The results are summarized in Table 2. All tests support the hypothesis that we deal with non-stationary data. On the other hand, we acknowledge that unit root tests are problematic from the methodological point of view and highly dependent on sample choice. 
Table 3 Group unit root tests (part I) - money market interest rates

\begin{tabular}{lcc}
\hline Test & Statistic & Probability \\
\hline Levin, Lin \& Chu t* & -0.78 & 0.22 \\
\hline Im, Pesaran and Shin W-stat & 0.18 & 0.57 \\
\hline ADF - Fisher Chi-square & 6.08 & 0.81 \\
\hline PP - Fisher Chi-square & 5.54 & 0.85 \\
\hline
\end{tabular}

Source: author's estimate

Table 3 Group unit root tests (part II) - FRAs

\begin{tabular}{lcc}
\hline Test & Statistic & Probability \\
\hline Levin, Lin \& Chu t* & -0.81 & 0.21 \\
\hline Im, Pesaran and Shin W-stat & 0.43 & 0.67 \\
\hline ADF - Fisher Chi-square & 7.71 & 0.90 \\
\hline PP - Fisher Chi-square & 7.84 & 0.90 \\
\hline
\end{tabular}

Source: author's estimate

\section{Forward premium}

We decided to restrict our empirical tests on FRAs. In the absence of a futures market, FRAs are the most reliable reflection of market expectations. We avoided using implied forwards. Our experience shows that implied forwards are less stable than FRAs and results are model dependent. This is especially true for less liquid markets.

\section{Descriptive statistics}

The first useful way to look at the forward premium is to compare forward rates with actual interest rates in the corresponding period. Basic descriptive statistics are provided in Table 4.

The data support expectation of a rising time premium hypothesis. The spread between actual 3M PRIBOR and 1 to 4 months FRA is not significant, but grows strongly for more distant FRAs. The shape of the distribution changes depending on the forward's horizon. The distributions become flatter and skewed toward higher spreads for more distant forwards. This reflects lower accuracy of long-term expectations. Considering the shape of the distribution we think that the median is better estimator of the forward premium than the average. The median is less sensitive to the positive skewness of the distribution and to occurrence of large observations. 
Table 4 Difference between FRAs and actual 3M Pribor

\begin{tabular}{|c|c|c|c|c|}
\hline Statistics & DFRA_1T04 & DFRA_3T06 & DFRA_6T09 & DFRA_9T012 \\
\hline Mean & 0.05 & 0.15 & 0.35 & 0.60 \\
\hline Median & 0.04 & 0.13 & 0.26 & 0.48 \\
\hline Maximum & 0.46 & 1.08 & 1.73 & 2.32 \\
\hline Minimum & -0.39 & -0.64 & -0.57 & -1.04 \\
\hline Std. Dev. & 0.14 & 0.32 & 0.51 & 0.71 \\
\hline Skewness & -0.01 & 0.26 & 0.32 & 0.34 \\
\hline Kurtosis & 3.96 & 3.23 & 2.50 & 2.53 \\
\hline
\end{tabular}

Source: author's estimate

\section{Forward regression}

The standard regression expectation theory test is based on Equation (2) that is transformed by subtracting the current level of interest rates (see Durre 2003) and rearranging terms. This transformation should overcome the possible non-stationarity of interest rates that could bias our estimates.

$$
\left(y_{t+h}^{3}-y_{t}^{3}\right)=\alpha+\beta^{*}\left(f_{t}^{(h, h+3)}-y_{t}^{3}\right)+\varepsilon_{t}
$$

We estimate the equation on a horizon of $1,3,6$ and 9 months corresponding to FRAs. The validity of the unbiased expectation theory would be confirmed by parameter values $a=0$ a $\beta=1$. A positive alfa parameter would imply a positive forward premium. The results are provided in Table 5 with parameter estimates in the first row and the t-test in the second. The third column includes $\mathrm{R}^{2}$ statistics. All results were obtained by using the Newey-West corrected covariance matrix to eliminate the bias caused by autocorrelated data.

The results support the expectations hypothesis. The beta parameter estimates are slightly above one and Wald's restriction test confirms that beta parameter estimates are not significantly different from one for all equations. We also imposed the restriction $\beta=1$ and estimated alfa parameters are in the last column (with reverse signs). They are equal to the sample averages and seem to have an upward bias as well. Models suffer from several weaknesses. Residuals are correlated and show ARCH effects. The Chow's and Quandt-Andrews breakpoint stability tests show that parameters are unstable. 
Table 5 Forward regression

\begin{tabular}{ccccc}
\hline Maturity & $\mathbf{a}$ & $\boldsymbol{\beta}$ & $\mathbf{r}^{\mathbf{2}}$ & $\mathbf{a I} \boldsymbol{\beta}=\mathbf{1}$ \\
\hline FRA_1to4 & -0.05 & 1.06 & 0.33 & 0.05 \\
\hline & -3.80 & 4.80 & & 4.24 \\
\hline FRA_3to6 & -0.15 & 1.02 & 0.34 & 0.15 \\
\hline & -3.58 & 5.90 & & 3.21 \\
\hline FRA_6to9 & -0.37 & 1.11 & 0.35 & 0.35 \\
\hline & -4.32 & 5.99 & & 4.02 \\
\hline FRA_9to12 & -0.63 & 1.11 & 0.31 & 0.60 \\
\hline & -4.79 & 5.63 & & 4.52 \\
\hline
\end{tabular}

Legend: Abbreviations in lines denote FRAs of different maturity, i. e. FRA_1to4 - FRA on $3 M$ PRIBOR starting in one month. Parameter estimates and $r^{2}$ statistics are in columns with t-statistics in italics. Parameter covariance matrix estimated by the Newey-West HAC method. Estimates correspond to percentage points.

Source: author's estimate

\section{ARCH models}

We concluded in the previous section that forward premium estimates are probably biased and residuals show ARCH effects. Thus, we decided to include the ARCH effect explicitly to remove the bias. We added a standard conditional variance equation.

$$
h_{t}=\alpha_{0}+\sum_{i=1}^{p} \varepsilon_{t-i}^{2}
$$

The ARCH effect was not significant for one month ahead FRA; for longer horizons we found only the first lag to be statistically significant. The results are shown in Table 6 . The support for $\beta=1$ hypothesis is weaker than in the constant variance test, but it was not rejected for any model at a $5 \%$ significance level by the Wald test. By imposing the $\beta=1$ restriction, we obtained risk premium estimates that are significantly lower than in the previous case.

Table 6 Forward regression with ARCH effect

\begin{tabular}{|c|c|c|c|c|c|}
\hline \multirow[t]{2}{*}{ Maturity } & \multicolumn{2}{|c|}{ Mean Equation } & \multicolumn{2}{|c|}{ Variance Equation } & \multirow{2}{*}{$\begin{array}{c}\text { Restricted } \\
\text { a } \\
\end{array}$} \\
\hline & $\mathbf{a}$ & $\boldsymbol{\beta}$ & $\mathbf{a}$ & $\operatorname{ARCH}(1)$ & \\
\hline \multirow[t]{2}{*}{ FRA_1TO4 } & -0.05 & 0.92 & 0.01 & 0.24 & 0.05 \\
\hline & -4.28 & 5.77 & 4.64 & 1.82 & 5.13 \\
\hline \multirow[t]{2}{*}{ FRA_3TO6 } & -0.17 & 0.52 & 0.02 & 0.94 & 0.15 \\
\hline & -12.25 & 4.78 & 3.88 & 5.85 & 10.61 \\
\hline \multirow[t]{2}{*}{ FRA_6TO9 } & -0.25 & 0.80 & 0.05 & 0.81 & 0.27 \\
\hline & -11.21 & 10.28 & 3.43 & 7.51 & 13.17 \\
\hline \multirow[t]{2}{*}{ FRA_9TO12 } & -0.36 & 0.97 & 0.06 & 0.91 & 0.36 \\
\hline & -12.40 & 19.25 & 3.73 & 8.21 & 15.73 \\
\hline
\end{tabular}

Legend: Abbreviations in lines denote FRAs of different maturity, i. e. FRA_1to4 - FRA on 3M PRIBOR starting in one month. Parameter estimates are in columns with $t$ statistics in italics. Estimates correspond to percentage points.

Source: author's estimate 


\section{Cointegration analysis}

Cointegration analysis has several advantages in comparison to the static approach. Firstly, it is suited for non-stationary data. Secondly, it enables to test causality and exogenity of variables. Thirdly, it interprets the relationship of variables in terms of long-term equilibrium and and short-term dynamic. On the other hand, there are also important weaknesses. Cointegration tests lack robustness, results depend on sample choice and we are not able to effectively deal with non-linearity often observed in the data.

We test the expectations theory by using the error correction framework. The two-dimensional error correction model is described by the following set of equations.

$$
\begin{gathered}
\Delta y_{t}^{3}=\alpha_{y} *\left(f_{t-1}^{(h, h+3)}-\beta^{*} y_{t-1}^{3}-\mu\right)+\sum_{i=1}^{p} a_{i}^{y f} * \Delta f_{t-i}^{(h, h+3)}+\sum_{i=1}^{p} a_{i}^{y y} * \Delta y_{t-i}^{3}+\varepsilon_{t}^{y} \\
\Delta f_{t}^{(h, h+3)}=\alpha_{f} *\left(f_{t-1}^{(h, h+3)}-\beta^{*} y_{t-1}^{3}-\mu\right)+\sum_{i=1}^{p} a_{i}^{f f} * \Delta f_{t-i}^{(h, h+3)}+\sum_{i=1}^{p} a_{i}^{f y} * \Delta y_{t-i}^{3}+\varepsilon_{t}^{f}
\end{gathered}
$$

Endogenous variables 3M Pribor and FRA interest rates appear on both sides of the equation. The error correction term is the first term on the right side with error correction parameters alfa. The rest of the terms track the correlation structure of variables. We choose the two-month lag length for all models to remove linear dependence. The lag length seems to be appropriate for all models with the exemption of 1 to 4 month forward, where the lag exclusion test clearly supported only a one month lag. This is no surprise because both instruments overlap for two months.

Our results are summarized in Table 7. The table starts with Johansen's cointegration test, where we report the trace statistics and corresponding $\mathrm{p}$-value. Johansen's test confirms that a cointegration vector exists for all forwards.

The second part of the table shows results of cointegration analysis. We imposed restrictions on the beta parameter in line with expectation theory, what allowed us to estimate the equilibrium forward premium directly from the cointegration vector. The results are in the middle column. The forward premium rises for more distant forwards and is statistically significant. The last column shows $p$-values for the standard parameter restriction. Data for all models support the expectation hypothesis that the parameter $\beta$ is not significantly different from one which is in line with expectation hypothesis. Error correction term parameters imply that interest rates behave as expected. There is clear a Granger causality from 
forwards to spot interest rates. This means that deviations from the equilibrium are corrected by spot rates. We also applied standard residual tests. The results of the Lagrange multiplier test do not indicate residual autocorrelation, but residuals suffer from ARCH effects and appear to be non-normal.

Table 7 Cointegration tests and vectors

\begin{tabular}{l|ccc|c|cc|c}
\hline \multicolumn{1}{c|}{ Vector } & \multicolumn{3}{|c|}{ Johansen's test } & VEC & \multicolumn{2}{c|}{$\begin{array}{c}\text { Error corr. } \\
\text { term }\end{array}$} & Restriction \\
& HO & Trace & p-value & Premium & MM 3M & FRA & p-value \\
\hline MM 3M & $j=0$ & $34.85^{*}$ & 0.00 & 0.04 & 0.75 & 0.36 & 0.99 \\
\hline FRA_1TO4 & $\mathrm{j}<=1$ & 3.96 & 0.42 & 4.13 & 3.88 & 1.42 & \\
\hline MM 3M & $j=0$ & $27.50 *$ & 0.00 & 0.10 & 0.32 & 0.16 & 0.68 \\
\hline FRA_3TO6 & $\mathrm{j}<=1$ & 3.55 & 0.48 & 3.50 & 4.60 & 1.40 & \\
\hline MM 3M & $j=0$ & $23.08^{*}$ & 0.02 & 0.23 & 0.21 & 0.09 & 0.73 \\
\hline FRA_6TO9 & $\mathrm{j}<=1$ & 3.91 & 0.43 & 4.98 & 4.77 & 1.18 & \\
\hline MM 3M & $j=0$ & $21.15^{*}$ & 0.04 & 0.40 & 0.15 & 0.02 & 0.80 \\
\hline FRA_9TO12 & $\mathrm{j}<=1$ & 4.21 & 0.38 & 5.73 & 4.35 & 0.38 & \\
\hline
\end{tabular}

Legend: Abbreviations in lines denote MM_3M for 3M PRIBOR and FRAs of different maturity (FRA_1to4 - FRA on 3M PRIBOR starting in one month...). * we reject $\mathrm{HO}$ hypothesis denoted by the number cointegration vectors, parameters $t$-statistics are in italics. Estimates correspond to percentage points.

Source: author's estimate

Cointegration models are better suited to test the expectations hypothesis than simply regression, but parameter values may not be constant especially in the context of the last ten years. The financial crisis caused a clear structural break in the development of many financial variables including money market interest rates, including FRAs. The impact is clearly visible from the development of the cointegration vector shown in Figure 2. Model residuals were exceptionally large as well, but only for equations that included money market interest rates.

Figure 2 Cointegration vector

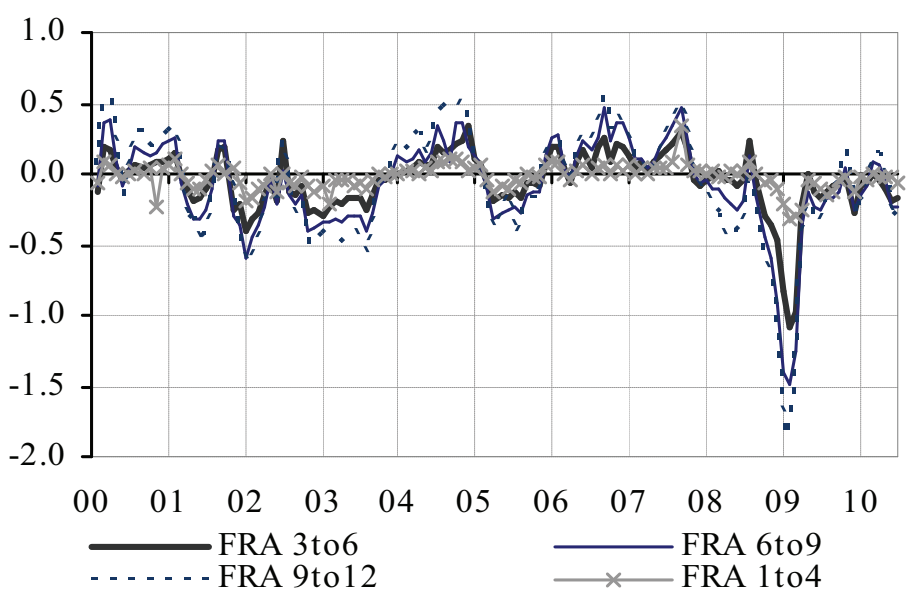

Source: author's estimate 
The drop in the cointegration vector occurred in autumn 2008 and disappeared quickly after February 2009. This may have impacted our results and we estimated all models on a shorter sample ending in mid-2008. The results were similar to full sample estimates and estimated parameter values differed by less than 2bp. It seems that FRAs were relatively gently impacted by the $2008 / 2009$ crisis with little evidence of long-lasting effects.

\section{Conclusion}

All estimates are summarized in Table 8. The highest estimates of the forward premium were obtained by forward regression and mean statistics. We consider these estimates biased and unreliable after theoretical and technical assumptions were violated. We prefer the median as the first guess estimator, because the statistic is robust to asymmetry observed in the empirical distribution. ARCH models proved to be helpful in removing bias shown by forward regression, but $\mathrm{ARCH}$ models largely ignore short-term dynamic that is driven by the monetary policy cycle and correlated forecasting errors. Finally, we think that cointegration framework offers best results. Error correction models enable to separate longterm equilibrium and short-term dynamic. Our estimates are in line with the biased expectations hypothesis and we also confirmed that forward premia recovered relatively briskly from the financial crisis. On the other hand, all methods assume the forward premium to be constant which may not be true. Costa (2007) shows that the forward premium is time-varying and its size reflects probability of capital losses for bond holders. This probability naturally increases when interest rates are expected to go up and is usually accompanied by positively skewed distribution of future interest rate changes. The asymmetric probability of future changes is then reflected in positive skewness of distribution. Relatively high estimates of the forward premium were also found for advanced markets (see Gürkaynak 2007). There are two possible explanations. Firstly, the forward premium also reflects the credit premium, but this is factor should be less important in the derivate market in comparison to the term premium. Secondly, investors may have overpredicted future interest rates in the past ten years that were marked by declining interest rates and unexpected disinflation over the period. 
Table 8 Forward premium estimates

\begin{tabular}{lcccc}
\hline Technique & FRA_1to4 & FRA_3to6 & FRA_6to9 & FRA_9to12 \\
\hline Mean & 0.05 & 0.15 & 0.35 & 0.60 \\
\hline Median & 0.04 & 0.13 & 0.26 & 0.48 \\
\hline Regression & 0.05 & 0.15 & 0.35 & 0.60 \\
\hline ARCH & 0.05 & 0.15 & 0.27 & 0.36 \\
\hline Cointegration & 0.04 & 0.10 & 0.23 & 0.40 \\
\hline $\begin{array}{l}\text { Legend: Abbreviations in columns denote FRAs of different maturity (FRA_1to4 - } \\
\text { FRA on 3M PRIBOR starting in one month...). } \\
\text { percentage points. }\end{array}$ &
\end{tabular}

Source: author's estimate

\section{$4 \quad$ Term premium}

The relation between policy rate and money market interest rates remains the key point of interest for market participants and policy makers. We define the term premium as the difference between the money market rate and policy rate or as the excess return of a term deposit above rolling-over two-week repo tenders. The key challenges for researchers are the impact of monetary policy, possible structural breaks, nonlinearities or heteroskedasticity in the data. We do not attempt to split the term premium into different categories because reliable risk-free benchmarks are not available for Czech money markets.

Firstly, we look at simple descriptive statistics. Secondly, we apply cointegration framework similarly to the forward premia section. Thirdly, we estimate ARCH models to reflect the nonlinearity observed in the data.

\section{Descriptive statistics}

The first step to estimate the term premium is to use simple descriptive statistics. We subtract the average policy rate from the corresponding money market rate to derive spreads. Policy rate is represented by the two-week repo rate which is a less risky instrument in comparison to the interbank deposit. We use linear approximation with the following formal expression.

$$
s_{t}^{m}=y_{t}^{m}-\frac{1}{m} * \sum_{i=1}^{m} C N B_{t+i-1}
$$

The results are summarized in Table 9. The spread of money market rates over policy rises with maturity. The distribution of spreads has high kurtosis and is skewed towards higher values. The mean may be biased upwards and so we prefer the median. The distribution gets flatter and volatility larger with rising maturity which reflects higher uncertainty of distant forwards. The weakness 
of simple statistics is that we assume stable distribution and that it may be biased by the presence of a relatively low number of tightening/easing periods in our sample.

Table 9 Descriptive statistics

\begin{tabular}{lcccccc}
\hline & S_1M & S_2M & S_3M & S_6M & S_9M & S_12M \\
\hline Mean & 0.11 & 0.17 & 0.24 & 0.37 & 0.48 & 0.59 \\
\hline Median & 0.05 & 0.08 & 0.13 & 0.23 & 0.32 & 0.39 \\
\hline Maximum & 1.07 & 1.37 & 1.66 & 2.18 & 2.44 & 2.66 \\
\hline Minimum & -0.17 & -0.08 & -0.11 & -0.12 & -0.16 & -0.23 \\
\hline Std. Dev. & 0.18 & 0.24 & 0.31 & 0.42 & 0.52 & 0.60 \\
\hline Skewness & 2.97 & 2.66 & 2.43 & 1.89 & 1.44 & 1.18 \\
\hline Kurtosis & 14.24 & 11.30 & 9.99 & 7.23 & 5.20 & 4.16
\end{tabular}

Legend: Abbreviations in columns denote spreads between different money market rates and actual two -week repo rate during the interbank deposits lifetime (s_1M is spread between monthly averages of $1 M$ PRIBOR and twoweek repo rate). Estimates correspond to percentage points.

Source: author's estimate

Sample statistics were surely impacted by the financial crisis and Table 10 confirms it. Pre-crisis distribution of term spreads is less skewed, has lower kurtosis and its mean is closer to the median. Both median and mean statistics are lower than in the full sample estimates.

Table 10 Term premium statistics - pre-crisis sample

\begin{tabular}{|c|c|c|c|c|c|c|}
\hline & S_1M & $S \_2 M$ & S_3M & S_6M & S_9M & $S \_12 M$ \\
\hline Mean & 0.04 & 0.06 & 0.10 & 0.20 & 0.30 & 0.41 \\
\hline Median & 0.04 & 0.06 & 0.08 & 0.17 & 0.25 & 0.32 \\
\hline Maximum & 0.15 & 0.25 & 0.33 & 0.69 & 1.06 & 1.47 \\
\hline Minimum & -0.17 & -0.08 & -0.11 & -0.12 & -0.16 & -0.23 \\
\hline Std. Dev. & 0.04 & 0.05 & 0.08 & 0.19 & 0.30 & 0.39 \\
\hline Skewness & -1.28 & 0.37 & 0.45 & 0.61 & 0.61 & 0.67 \\
\hline Kurtosis & 9.01 & 4.65 & 3.60 & 2.81 & 2.59 & 2.69 \\
\hline
\end{tabular}

Source: author's estimate

\section{Cointegration}

Theoretically, cointegration is well-suited for estimates of term spread in the money markets. Most importantly, it enables to decompose the relationship between policy rates and different money market rates on a short-term and long-term "equilibrium" part. On the other hand, we still assume the "equilibrium" premium to be constant. 
The necessary condition for cointegration is non-stationarity of underlying variables. The tests are represented in the appendix and they support the non-stationarity hypothesis. Similarly to the forward premium section, we will use an error correction framework that may be described by the following set of equations.

$$
\begin{gathered}
\Delta y_{t}^{m}=\alpha_{y} *\left(c n b_{t-1}-\beta^{*} y_{t-1}^{m}-\mu\right)+\sum_{i=1}^{p} a_{i}^{y c n b} * \Delta c n b_{t-i}+\sum_{i=1}^{p} a_{i}^{y y} * \Delta y_{t-i}^{m}+\varepsilon_{t}^{y} \\
\Delta c n b_{t}=\alpha_{c n b} *\left(c n b_{t-1}-\beta^{*} y_{t-1}^{m}-\mu\right)+\sum_{i=1}^{p} a_{i}^{c n b c n b} * \Delta c n b_{t-i}+\sum_{i=1}^{p} a_{i}^{c n b y} * \Delta y_{t-i}^{m}+\varepsilon_{t}^{c n b}
\end{gathered}
$$

The money market rate of maturity $\mathrm{m}$ and the average two-week repo rate appear on both sides of the equations. The equilibrium or cointegrating equation is described by $c n b_{t}=\beta^{*} y_{t}^{m}+\mu$ with the error correction parameter alfa. The rest of the terms track the correlation structure of variables.

Cointegration tests failed to prove a cointegration relationship between policy rate and money market rates, although the necessary condition was met and fundamental logic also supports the expectation of a cointegration relationship. We think that the structural break during the crisis period is the key reason. We reduced the length of the sample to the January 2000 - June 2007 period. In this shorter sample, the data support cointegration hypothesis decisively. Results are in Table 11.

All models were estimated with a three-month lag that was supported by standard tests. The cointegration vector shows that term spread rises with maturity and is statistically significant. The last column shows p-values for parameter restriction. Data for all models support the hypothesis that the parameter $\beta$ is not significantly different from unity which is in line with the expectation hypothesis. Only one-month maturity is an exemption. The error correction parameters have expected sign, but only policy rate parameters are statistically significant. Thus, disequilibrium is eliminated by policy rates, which is consistent with expectation theory. Residuals seem to be uncorrelated, but suffer from $\mathrm{ARCH}$ effects and are non-normal (money market interest rate components). 
Table 11 Term premium estimates

\begin{tabular}{|c|c|c|c|c|c|c|c|}
\hline \multirow[t]{2}{*}{ Vector } & \multicolumn{3}{|c|}{ Johansen's test } & \multirow{2}{*}{\begin{tabular}{|c} 
VEC \\
Premium
\end{tabular}} & \multicolumn{2}{|c|}{$\begin{array}{c}\text { Error } \\
\text { correction } \\
\text { term }\end{array}$} & \multirow{2}{*}{$\begin{array}{c}\text { Restriction } \\
\text { p-value }\end{array}$} \\
\hline & HO & Trace & p-value & & MM & cnb & \\
\hline $\mathrm{cnb}$ & $j=0$ & $62.7 *$ & 0.00 & 0.04 & 0.00 & 0.70 & 0.01 \\
\hline MM 1M & $j<=1$ & 8.16 & 0.07 & 7.64 & 0.00 & 2.17 & $\operatorname{lag}=3$ \\
\hline cnb & $j=0$ & 50.54* & 0.00 & 0.06 & 0.08 & 0.72 & 0.17 \\
\hline MM 2M & $\mathrm{j}<=1$ & 3.60 & 0.47 & 6.85 & 0.41 & 4.04 & $\operatorname{lag}=3$ \\
\hline $\mathrm{cnb}$ & $j=0$ & $40.17 *$ & 0.00 & 0.09 & 0.10 & 4.64 & 0.33 \\
\hline MM 3M & $\mathrm{j}<=1$ & 2.80 & 0.62 & 7.26 & 0.65 & 0.61 & $\mathrm{lag}=3$ \\
\hline $\mathrm{cnb}$ & $j=0$ & $28.35^{*}$ & 0.00 & 0.17 & 0.03 & 0.36 & 0.54 \\
\hline MM 6M & $\mathrm{j}<=1$ & 3.58 & 0.48 & 7.53 & 0.22 & 4.09 & $\operatorname{lag}=3$ \\
\hline cnb & $j=0$ & $26.81 *$ & 0.01 & 0.26 & 0.05 & 0.25 & 0.49 \\
\hline MM 9M & $\mathrm{j}<=1$ & 4.87 & 0.30 & 7.62 & 0.47 & 3.60 & $\operatorname{lag}=3$ \\
\hline $\mathrm{cnb}$ & $j=0$ & $24.3^{*}$ & 0.01 & 0.34 & 0.06 & 0.18 & 0.48 \\
\hline MM 12M & $j<=1$ & 2.88 & 0.20 & 7.44 & 0.68 & 3.28 & $\operatorname{lag}=3$ \\
\hline
\end{tabular}

Legend:CNB denotes CNB's two-week repo rate. Other abbreviations in lines denote money market rates of different maturity (MM $1 M$ is one month PRIBOR). Parameters $t$-statistics are in italics. * We reject $\mathrm{HO}$ hypothesis denoted by the number of cointegration vectors. Estimates correspond to percentage points.

Source: author's estimate

\section{ARCH models}

Money market interest rates exhibit heteroscadasticity with a structural break in the crisis period. A standard approach on how to deal with heteroscadastic data is to use GARCH models, although they are not well-suited to deal with the structural break. We found a useful inspiration in Engle (1987), but we decided to avoid ARCH-M specification, which includes the time-varying variance in the mean equation. We find this approach misleading. The methodology is not able to remove the impact of the monetary policy cycle from the data. The ARCH-M model will then interpret the forecasting error as a part of the timevarying risk premium.

We tested several variants of the $\operatorname{GARCH}(p, q)$ specification, but finally decided to only use $\mathrm{ARCH}(\mathrm{p})$ models because "value added" of more complicated models was very limited. We used term spread as dependent variable in the mean equation and we assumed constant mean. Conditional variance equation is depicted in equation (5). Our results are presented in Table 12. For every maturity we present a model that minimized the Bayesian information criterion. 
Table 12 Term premium estimates

\begin{tabular}{ccccc}
\hline \multirow{2}{*}{ Maturity } & \multicolumn{2}{c}{ Mean Equation } & \multicolumn{2}{c}{ Variance Equation } \\
& Constant & Constant & ARCH(1) & ARCH(2) \\
\hline S_1M & 0.05 & 0.00 & 1.53 & - \\
& 13.10 & 2.67 & 3.77 & - \\
\hline S_2M & 0.07 & 0.00 & 1.26 & - \\
& 15.52 & 2.29 & 2.81 & - \\
\hline S_3M & 0.10 & 0.00 & 0.76 & 0.43 \\
& 21.58 & 3.05 & 2.84 & 2.19 \\
\hline S_6M & 0.14 & 0.00 & 1.15 & - \\
& 21.13 & 4.77 & 7.79 & - \\
\hline S_9M & 0.19 & 0.02 & 0.95 & - \\
& 14.79 & 3.05 & 9.52 & - \\
\hline S_12M & 0.28 & 0.02 & 1.01 & -0.08 \\
& 19.68 & 3.85 & 11.25 & -2.95 \\
\hline
\end{tabular}

Legend: Abbreviations in rows denote spreads between different money market rates and actual two-week repo rate during interbank deposits lifetime (s_1M is spread between monthly averages of $1 M$ PRIBOR and two-week repo rate). Parameters z-statistics are in italic. Estimates correspond to percentage points.

Source: author's estimate

Although $\mathrm{ARCH}$ models proved to be a useful tool to capture some sources of non-stationarity in the data, they are not able to reflect the shift in the mean that occurred during the financial crisis. The structural break is clearly visible from the residual as shown in Figure 3.

Figure 3 Selected ARCH models residuals

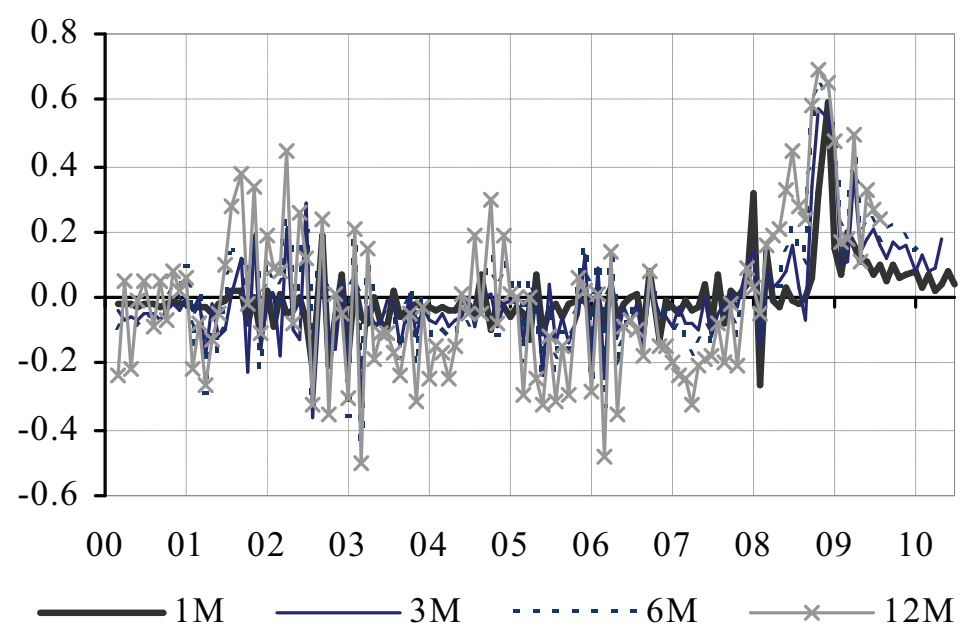

Source: author's estimate

The shock was persistent, although it gradually faded away. The structural break may have impacted our estimates of the term premium and therefore, we estimated all models only for the pre-crisis period ending in June 2007 similarly 
to the cointegration analysis. The premia estimates were similar to full sample results, but $\mathrm{ARCH}$ effects became statistically insignificant. From this point of view, $\mathrm{ARCH}$ models seem to be a robust technique in case we deal with structural breaks and non-stationarity in the data.

A closer look at residuals also may give an idea of persistence of the structural shock. Model residuals reached the maximum mostly in October 2010, when the financial crisis also culminated in most segments of financial markets. The elevated risk premia, as measured by residuals, started to gradually fade away. Normalization was faster for shorter maturities, which is also in line with evidence from foreign money markets.

Table $13 \mathrm{ARCH}$ models - residuals in bp

\begin{tabular}{lcccccc}
\hline Maturity & $\mathbf{- 6 M}$ & $\begin{array}{c}\text { Peak } \\
\text { value }\end{array}$ & $\begin{array}{c}\text { Peak } \\
\text { month }\end{array}$ & $\mathbf{+ 6 M}$ & $\begin{array}{c}\text { Last } \\
\text { value }\end{array}$ & $\begin{array}{c}\text { Last } \\
\text { month }\end{array}$ \\
\hline S_1M & 3 & 59 & $2008: 11$ & 11 & 4 & $2010: 06$ \\
\hline S_2M & -6 & 65 & $2008: 10$ & 25 & 3 & $2010: 05$ \\
\hline S_3M & 5 & 58 & $2008: 10$ & 14 & 18 & $2010: 04$ \\
\hline S_6M & 3 & 68 & $2008: 10$ & 11 & 18 & $2010: 01$ \\
\hline S_9M & 12 & 68 & $2008: 10$ & 9 & 24 & $2009: 10$ \\
\hline S_12M & 20 & 69 & $2008: 10$ & 10 & 24 & $2009: 07$ \\
\hline
\end{tabular}

Legend: Abbreviations in rows denote spreads between different money market rates and actual two-week repo rate during interbank deposits lifetime (s_1M is spread between monthly averages of $1 M$ PRIBOR and two-week repo rate).

Source: author's estimate

\section{Summary}

Table 14 provides a summary of our estimates. We may conclude that the term spread rises with maturity and that estimation methods differ in their sensitivity to structural breaks and non-stationarity in the sample. Full sample estimates that include the crisis period are higher for all methods and the mean is especially sensitive to extreme observations. The ARCH model provides similar estimates for the full sample and pre-crisis sample period, but the error correction model gives useful estimates only for the pre-crisis period. Again, we believe that the median may give a useful first guess estimate with other techniques giving more precise estimates, but we should keep in mind that every method has its weaknesses. 
Table 14 Term premium - summary

\begin{tabular}{lcccccc}
\hline Method & MM 1M & MM 2M & MM 3M & MM 6M & MM 9M & MM 12M \\
\hline \multicolumn{7}{c}{ Pre-crisis sample (2000:01-2007:06) } \\
\hline Mean & 0.04 & 0.06 & 0.10 & 0.20 & 0.30 & 0.41 \\
\hline Median & 0.04 & 0.06 & 0.08 & 0.17 & 0.25 & 0.32 \\
\hline Cointegration & 0.04 & 0.06 & 0.09 & 0.17 & 0.26 & 0.34 \\
\hline ARCH & 0.04 & 0.07 & 0.10 & 0.13 & 0.19 & 0.26 \\
\hline \multicolumn{7}{c}{ Full sample (2000:01-2010:06) } \\
\hline Mean & 0.11 & 0.17 & 0.24 & 0.37 & 0.48 & 0.59 \\
\hline Median & 0.05 & 0.08 & 0.13 & 0.23 & 0.32 & 0.39 \\
\hline ARCH & 0.05 & 0.07 & 0.10 & 0.14 & 0.19 & 0.28 \\
\hline
\end{tabular}

Legend: Abbreviations in columns denote money market rates of different maturity (MM 1M is one month PRIBOR). Estimates correspond to percentage points.

Source: author's estimate

\section{$5 \quad$ Concluding remarks}

The last ten years were remarkable for Czech money markets. Key interest rates have normalized to levels typical in advanced economies. The financial crisis provided considerable stress for all segments of financial markets including money markets. Risk premia widened abruptly following the disintegration of markets after Lehman Brother's collapse. Unfortunately, we lack a reliable risk-free benchmark in the Czech money market and, therefore, it is impossible to provide an accurate decomposition of money market rates into a risk-free part and risk premium. Instead, we focused on key risk premia implied by the expectation hypothesis framework - the forward premium and the term premium. Our analysis showed that forward premia were relatively stable during the financial crisis and they normalized quickly. The results generally support the biased expectation hypothesis, but estimates differ significantly depending on estimation methods. We argue that medians may provide the first guess estimate of the forward premium, but $\mathrm{ARCH}$ models and cointegration techniques are better suited to deal with non-stationarity observed in the data. We consider the forward premium to be relatively high and we see two possible explanations. Firstly, the forward premium also reflects the credit premium, but this factor should be less important in the derivative market in comparison to the term premium. Secondly, investors may have overpredicted the future interest rate in the past ten years, marked by declining interest rates and unexpected disinflation during the period. A similar conclusion can be drawn from the term premium analysis, although the impact of the financial crisis was heavier. Our estimates show a clear structural break during the crisis period, but elevated premia considerably declined later. Methods that explicitly or implicitly assume a stable term premium fail or provide biased estimates. Again, medians seem to 
be a relatively robust estimator that less sensitive to nonlinearities and parameter instability observed in the data. We found $\mathrm{ARCH}$ models to be useful as timedependent variance enables to absorb a significant part of the shock that occurred during the financial crisis.

\section{References}

Costa, S. - Galvão, B. A. (2007). The Forward Premium of Euro Interest Rates. Lisboa: Bank of Portugal. Retrieved from: http://ideas.repec.org/p/ptu/wpaper/ w200702.html

Czech National Bank (2009). Financial Stability Report 2008/2009. Prague: CNB. Retrieved from: http://www.cnb.cz/en/financial_stability/fs_reports/

Czech National Bank (2010). Financial Stability Report 2009/2010. Prague: CNB. Retrieved from: http://www.cnb.cz/en/financial_stability/fs_reports/

Durré, A. - Snorre, E. - Pilegaard, R. (2003). Estimating Risk Premia in Money Market Rates. ECB. Retrieved from: www.ecb.int/pub/pdf/scpwps/ecbwp221.pdf

European Central Bank (2008). Financial Stability Review - December 2008, Frankfurt: ECB. Retrieved from http://www.ecb.int/pub/fsr/html/index.en.html

European Central Bank (2010). Euro Money Market Survey 2010. Frankfurt: ECB. Retrieved from: http://www.ecb.int/press/pr/date/2010/html/pr100923.en.html

Engle, R. F. - Lilien, D. M. - Robins, R. P. (1987). Time Varying Risk Premia in the Term Structure: The Arch-M Model. Econometrica. Econometric Society, 55(2), pp. 391-407.

Gravelle, T. - Muller P. - Stréliski D. (1998). Towards a New Measure of Interest Rate Expectations in Canada: Estimating a Time-Varying Term Premium. Bank of Canada. Retrieved from: www.bank-banque-canada.ca/en/conference/con98/ cn98-11.pdf

Gürkaynak, R. S. - Sack, B. P. - Swanson, E. T. (2007). Market-Based Measures of Monetary Policy Expectations. Journal of Business \& Economic Statistics, 25(2), pp. 201-212.

International Monetary Fund (2008). Stress in Bank Funding Markets and Implications for Monetary Policy. Global Financial Stability Report - October 2008. IMF, pp. 69-104. Retrieved from: http://www.imf.org/external/pubs/ft/GFSR/ index.htm

Kotlán, V. (1999). Výnosová křivka v teorii a praxi českého mezibankovního trhu (The Yield Curve in Theory and in Practice of the Czech Interbank Market), Czech Journal of Economics and Finance, 49(7), pp. 407-426. 
Pohl M. (2010). Czech Swap Market in the Crisis Period, paper presented at 2nd International Conference "Economies of Central and Eastern Europe: Convergence, Opportunities and Challenges" in Tallin. 